\title{
Qualitative Risk Assessment of Cyberattacks on Power Systems
}

\author{
H. E. Brown \\ University of Wisconsin-Madison \\ 1415 Engineering Drive \\ Madison, WI 53706 \\ brown.hilaryeieee.org
}

\begin{abstract}
For almost 100 years, attacks on the electric infrastructure of a country have been identified as key vulnerabilities during times of war. Homegrown radical environmental groups and separatist movements in other countries have all waged war on the electric power system by physically attacking the infrastructure. The threat of cyberattacks has grown as telecommunication technologies are increasingly deployed as part of the electric infrastructure. This paper will discuss the risk of power grid attacks from a sociological perspective, focusing on attacks orchestrated to cause widespread blackouts rather than annoyance. In particular, this paper will describe the motivation and symbolism of historical attacks, as well as the qualitative elements of this risk, the role of the public in decision-making, and how the risk has been communicated to the public through the media.
\end{abstract}

\section{CCS CONCEPTS}

- Security and Privacy $\rightarrow$ Social aspects of security and privacy - Networks $\rightarrow$ Network types; Cyber-physical networks

\section{KEYWORDS}

Power systems, risk communication

\footnotetext{
Permission to make digital or hard copies of all or part of this work for personal or classroom use is granted without fee provided that copies are not made or distributed for profit or commercial advantage and that copies bear this notice and the full citation on the first page. Copyrights for components of this work owned by others than ACM must be honored. Abstracting with credit is permitted. To copy otherwise, or republish, to post on servers or to redistribute to lists, requires prior specific permission and/or a fee. Request permissions from Permissionseacm.org.

CyberSec '18, April 9-11, 2018, Coeur d' Alene, ID, USA

(C) 2018 Association for Computing Machinery.

ACM ISBN 978-1-4503-6406-5/18/04 \$15.00

https://doi.org/10.1145/3212687.3212867
}

\section{ACM Reference format:}

H. E. Brown. 2018. Qualitative Risk Assessment of Cyberattacks on Power Systems. In CyberSec '18, April 9-11, 2018, Coeur d'Alene, ID, USA, 6 pages. https://doi.org/10.1145/3212687.3212867

\section{INTRODUCTION}

Power systems supplying electricity to billions of people stretch over thousands of miles in many countries, and connect to one another across international borders. Commonly, the power system is subdivided into generation, transmission, and distribution. The generation system comprises large generators that transform energy from fuel (coal, gas, water) into electricity. The transmission system is made up of towers and high voltage conductors (larger than $69 \mathrm{kV}$ ) that allow electricity to be transferred over large distances. It also includes substations, which contain circuit breakers to protect equipment from damage and transformers to convert between low and high voltages. The distribution system supplies power at lower voltages to industrial, commercial, and residential consumers. The control system may be considered a fourth subsystem, although its equipment and functions are present throughout the other three areas.

Attacks on physical infrastructure are a common and known vulnerability of geographically-dispersed electric power grids. Destroying electricity supplies can result in varying degrees of damage, depending on the scope of the attack and availability of alternative supplies, like back-up generators. The hazards of widespread power outages spread beyond blackouts to other infrastructure systems that require electricity to function properly [1]: municipal water, natural gas, shipping, and refrigeration. Electrical infrastructure has been targeted by the 
American military in international conflicts since WWII [2], as well as by various marginalized groups, such as eco-terrorists [3, 4], rebel guerillas [3], and disaffected workers but the latter has been more on the scale of vandalism [3, 5].

In 2013, an attack on Metcalf substation (owned by Pacific Gas and Electric) emphasized the ongoing nature of this vulnerability. After cutting fiber-optic cables to the substation, snipers disabled seventeen large power transformers in just nineteen minutes [6]. It was reported that the Metcalf attack was one of "274 significant instances of vandalism or deliberate damage in... three years" and that "terrorist organizations were linked to 2,500 [overseas] attacks on transmission lines or towers and at least 500 on substations from 1996 to 2006" [6]. In Arkansas during 2013, an individual attacked the power system four times in less than three months, causing over $\$ 4.5$ million of damage before being apprehended [7, 8]. Recent studies commissioned by the Federal Energy Regulatory Commission (FERC) indicate that coordinated attacks on just nine substations could cause a blackout lasting several weeks, if not longer [9].

Given the popularity of power systems as a physical target for a wide variety of groups, it makes sense to worry about attacks on power systems via telecommunications (i.e. cyberattacks). In re-cent years, more and more grid equipment has been inter-connected and is now monitored using telecommunications technology. In 2007, a Department of Homeland Security (DHS) test demonstrated a vulnerability called "AURORA." They destroyed a generator in a cloud of billowing smoke by repeatedly opening and closing its circuit breaker to induce a stressful condition called "out-of-step" $[10,11]$. One year later, FERC found that 23 of 30 audited utilities had failed to adequately protect against AURORA [12]. And in 2014, more than 800 pages of documents on AURORA were accidentally released into the public domain after a Freedom of Information Act request for documentation on a different Aurora attack [13]. Some commentators believed that 2015 would be the year of AURORA [12, 13], although no reports of successful AURORA attacks have yet surfaced.

\section{QUALITATIVE ASPECTS OF CYBERATTACK RISK}

In one classic article on the sociological evaluation of risk, the qualitative dimensions of risk are described: voluntariness, im-mediacy, knowledge about the risk, novelty, controllability, acuity, common/dread, and severity of consequences [27]. Voluntariness refers to the ability of a person to choose a risk; sky-diving is an example of a voluntary risk. Although some people live off-grid, most others depend on electricity for almost everything in their daily lives. Thus, the risk of a blackout caused by attacks on infrastructure is involuntary. Immediacy refers to how quickly damage occurs. Blackouts are instantaneous, but if power is restored within a couple days, most people would be able to survive with flashlights, bottled water, and canned goods, as during weather-induced outages. Those who are most dependent on electricity, such as hospital patients, the elderly, and young children may risk death during a longlasting blackout, especially if emergency power supplies fail.

Knowledge about risk refers to how familiar the public is with the risk. The public is certainly aware of the risk of blackouts, since most people have experienced power outages. Members of the public who frequently read publications like The Washington Post are probably aware of the risk of attack-induced blackouts, extensively covered after the attacks on Metcalf substation $[6,9,28-31]$. Others may have read news reports about the successful cyberattack of Ukraine's power grid. The hazards of widespread blackouts caused by attacks are familiar to utilities and policy-making groups related to power systems and have been discussed in many reports, see $[1,3,5,24,32]$ for examples. One interesting note is that the number of vulnerabilities is unknowable; Schneier makes this point for cyberattacks [25], but it holds equally true for physical attacks. The ways in which adversaries can attack electric power systems are limited only by their creativity. Thus, knowledge about how attacks might happen is limited, even though the risks of attack are fairly well known.

Another qualitative dimension of risk is controllability. How much can an individual control the risk through either preparation or ingenuity? In considering attacks on the electricity infrastructure, individuals have many opportunities to mitigate the risks induced by long-term outages. People can prepare by stockpiling food and water. A 
Qualitative Risk Assessment of Cyberattacks on Power Systems

smaller subset of people may wish to prepare by purchasing a small generator and fuel to provide for their household's essential needs during a long-term outage. Others may choose to install renewable energy systems with on-site storage that can operate disconnected from the grid.

The novelty of a risk affects how the public perceives it. The electrical system is well over 100 years old and physical infrastructure attacks have been described since the interwar period. Cyberattacks, on the other hand, are a new risk. Before Stuxnet, most people believed that airgapped equipment was secure because it was not attached to the wider telecommunications networks where cyberattacks originate. Within the range of possible cyberattacks, those that attack control systems to initiate improper control action are considered unlikely and uncommon, although AURORA, stuxnet, and the Ukrainian attack have shown that the possibility is non-trivial.

Acuity can be divided into two categories: chronic and catastrophic. The risk itself is chronic-attacks could happen at any time, so it requires ongoing mitigation. The acuity of an attack's aftermath depends on how long it takes to restore power and the breadth of the attack. For example, recovery from an attack causing blackouts in all three U.S. grids would be different than one which only caused a blackout in one grid. However, power systems engineers and operators have experience dealing with generation shortfalls and outages: using brownouts, rolling blackouts, and restoration plans. Thus, it is actually quite difficult to determine whether the results of power system attacks would be chronic or catastrophic or neither.

The dichotomy between common and dread risks affect how they are perceived by the public. Most people have experienced power outages, making the initial phases of a blackout "common." As a result, some people may underestimate how disruptive long-term outages would be and not dread the occurrence. For those who do recognize the possibility of disruption, a lasting outage would inspire dread. People may worry about how society can continue without electricity for health care and water and food supplies. The popularity of books describing postapocalyptic conditions indicate some level of collective dread about the breakdown of modern society, which depends on electricity [33].

The last qualitative aspect of risk described in [27] is the severity of the
CyberSec '18, April 9-11, 2018, Coeur d' Alene, ID, US

consequences. How many fatalities would occur? Would it result in widespread contamination of the environment? In power system attacks, fatalities are certainly possible, but would probably not occur on large scales. Order of magnitude estimates could be based on the number of deaths outages caused by weather. However, weatherrelated fatalities may overstate the death rate, including fatalities due to the weather itself, like flooding. The work required to restore the grid to an operational state would place many linemen and other electrical workers at increased risk of workplace injury, as they work long hours to fix the grid under uncertain conditions.

If one excludes attacks on nuclear power plants, it is not expected that people would place an outsized concern on the risk of cyberattacks directed at the power system, compared to a traditional risk assessment. Although the risk of cyberattack is fairly novel and the chronic nature of cyber vulnerabilities (24 hours a day, 7 days a week) adds a sense of urgency, it is not dread-inspiring and there would be few immediate fatalities.

\section{COMMUNICATING CYBERATTACK RISK}

Despite the fact that the greater public would be affected by a cyberattack on power systems infrastructure, the public has only limited involvement in the decision-making process to mitigate the risk. The primary decision-makers are utilities, generation companies, Congress, FERC, and the North American Electric Reliability Corporation (NERC). The US Congress has not passed legislation that deals directly with the cyber vulnerabilities of the power system despite several hearings on the topic [12, 15, 34]. FERC is the federal agency tasked with regulating interstate transmission of electricity, while NERC develops standards and enforces compliance to ensure the reliability of the North American power grid. After the attack on the Metcalf substation, FERC asked NERC to develop standards about the physical security of critical assets [29]. FERC, as a federal agency, posts notices of proposed rulemaking and also has extended periods of public comment. Although NERC comprises members of the electric power industry, it opens up proposed standards for extended comment periods when public input may be provided. In these comment periods, both 
individuals and companies may submit comments.

Still, many decisions on cybersecurity are left to utilities as most mandatory NERC standards apply only to "critical" assets, determined by the utility itself with some guidelines. For example, "[t]ransmission substations that support the reliable operation of the Bulk Electric System" should be considered "critical" [35]. Beyond guidelines from NERC, companies engage in their own risk assessment. A recent report describes a wide range of cyber-security failure scenarios to help utilities perform risk assessment using impact scores, likelihood and opportunity [32]. The report recommended incorporating qualitative aspects of risk assessment into the impact criteria, for example, loss of privacy and goodwill.

Communication about the risks of physical and cyberattacks on the power grid is not always clear. Utilities are loathe to communicate this risk to the public because they do not want to exacerbate the problem by inspiring others to undertake similar attacks. A spokesman for Pacific Gas and Electric declined to comment after the Metcalf attack for "fear of giving information to potential copycats" [6]. The media, however, have no qualms about reporting on the issue and most take a fairly alarmist tone [34], with one or two quotes from industry spokespeople downplaying the risk because the grid's resilient design [9], [6], [36]. But some argue that the grid is actually "brittle" not resilient by design [24]. Recently, the Cyber squirrel 1 website has gained widespread media attention by humorously comparing the large number of power outages caused by woodland creatures to the miniscule amount of known cyberattacks [37].

Cost-benefit analyses of risk assessment for low probability, high consequence events are difficult because mitigation measures may not appear to be cost-effective when the probability is so low. Reference [12] highlights the tension between protecting against events with low probability but large consequences, also noted in [1]. The former director of the security program that identified AURORA "argues that there is too much reliance within the power industry on risk-based calculations taken from the business world, that are ill-suited to the protection of critical national infrastructure... the cost of failure is so high that utilities should hold themselves to a higher standard" [12]. By downplaying these risks, utilities actually inflict an involuntary risk on their customers. Utilities could include funding for such cyberattack mitigation in their rate plans and, even if that part of the rate was not approved, at least the public would be more aware of the risk and have exercised some input into the process.

\section{CONCLUSIONS}

Overall, the electricity infrastructure is vulnerable to all sorts of physical and cyberattacks and has experienced numerous attacks on a small scale for many, many years. From monkey-wrenchers to cybercriminals, the power grid has historically been frequently targeted. Attacks on the power grid seem to be less of a concern from the public's perspective when examining the qualitative aspects of risk in [27]. The results of such attacks, while not insignificant, seem familiar because most people have experienced power outages and they appear controllable. Perhaps due to public indifference to attack-induced blackouts, the public is not actively involved in decisions about risk mitigation. Utilities make most mitigation decisions internally, while FERC and NERC provide mandatory regulations for certain looselydefined protective measures with periods of public comment. Recommended procedures for completing risk assessments on cybersecurity failure scenarios do include qualitative aspects of each risk, such as loss of confidence, loss of privacy, and longer customer service times.

Cyberattacks on the power grid are low probability, high consequence events, making mitigation difficult. However, the potential for sophisticated state-sponsored cyberattacks intensifies the risk of widespread outages that may extend beyond the grid's designed resilience. Utilities should be doing more to mitigate against cyberattacks and to protect critical substations from physical attack. The latter is manageable, with FERC studies indicating a subset of thirty especially critical substations and other speculating that the total number is less than one hundred [9]. The former is the most challenging to mitigate and also the most dangerous, given the increasing number of cyberattacks and an unknowable amount of vulnerabilities in the control systems. 
Qualitative Risk Assessment of Cyberattacks on Power Systems

\section{ACKNOWLEDGMENTS}

The author thanks Drs. Vicki Bier and Christopher DeMarco. This research was supported in part by the U.S. Dept. of Energy Lawrence Berkeley National Laboratory, through the project "Algorithmic/Computational Research within Power System Vulnerability," under a prime contract No. DE-AC02-05CH11231. Work presented here was also funded in part by the Advanced Research Projects Agency-Energy (ARPA-E), U.S. Dept. of Energy, under Award Number DE-AR0000717. The author gratefully acknowledges these sources of support; however, views and opinions of the author expressed herein do not necessarily state of reflect those of the United States Government or any agency thereof.

\section{REFERENCES}

[1] "Quadrennial Energy Review: Energy Transmission, Storage, and Distribution Infrastructure," Dept. of Energy, Washington, DC, USA, Apr. 2015. [Online] http://energy.gov/epsa/quadrennial-energy-reviewqer. Accessed: 4/30/15.

[2] T. E. Griffith, "Strategic attack of national electrical systems," Advanced Airpower Studies, Maxwell Air Force Base, AL, USA, Oct. 1994.

3] "Physical vulnerability of electric systems to natural disasters and sabotage," U.S. Congr. Office of Tech. Assessment, Washington, DC, USA, OTA-E453,1990 .

[4] Anonymous, "Powerlines," in Ecodefense: A field guide to monkeywrenching, D. Foreman and B. Haywood, Eds., 3rd ed, 1993, pp. 77-80.

[5] Nat Research Council of the Nat Academies, "Terrorism and the electric power delivery system," The Nat. Academies Press. Washington, DC, USA, 2002 .

[Online]

http://www.nap.edu/catalog/12050/terrorismand-theelectric-power-delivery-system. Accessed: 2/11/16.

[6] R. Smith, "Assault on California power station raises alarm on potential for terrorism; April sniper attack knocked out substation, raises concern for country's power grid," The Wall street Journal, Feb. 4, 2014.

[7] Attacks on Arkansas power grid: Perpetrator sentenced to 15 years. Federal Bureau of Investigation, Aug. 10, 2015. [Online] https://www.fbi.gov/

news/stories/attacks-on-arkansas-power-grid Accessed: 1/24/16.

[8] W. Stephenson, "The story of Jason Woodring, the Arkansas power grid vandal," The Arkansas Times, June 12, 2014 [Online] http: //www. arktimes.com/arkansas/the-story-ofjason-woodring-the-arkansas-power-gridvandal/Content?oid=3334926. Accessed: 10/13/16.

[9] R. Smith, "U.S. risks national blackout from smallscale attack; Federal analysis says sabotage of nine key substations is sufficient for broad outage," The Wall Street Journal, Mar. 12, 2014.

[10] M. Swearingen, S. Brunasso, J. Weiss, and D. Huber, "What you need to know (and don't) about the AURORA vulnerability," Power. Sept. 1, 2013. [Online] http://www. powermag.com/what-you-need-to-know-anddont-about-the-aurora-vulnerability/?printmode=1 Accessed: 4/30/15.

[11] "Staged cyber attack reveals vulnerability in power
CyberSec '18, April 9-11, 2018, Coeur d' Alene, ID, US

grid,"

2007

[Online]

https: / /www. youtube. com/watch? v=fJyWngDco3g Accessed: 5/3/15.

[12] P. F. Roberts, "If cyberwar wrupts, America's electric grid is a prime target," The Christian Science Monitor, Dec. 23, 2014. [Online] http:// www.csmonitor.com/World/Passcode/2014/1223/Ifcyberwar-erupts-America-s-electric-grid-is-a-primetarget. Accessed: 5/2/15.

[13] P. Tucker, "Forget the Sony hack, this could be the biggest cyber attack of 2015," Defense One, Dec. 14, 2014. [Online] http://www.defenseone.com/ technology/2014/12/forget-sony-hack-could-be-hebiggest-cyber-attack-2015

$101727 /$ Accessed 5/4/15.

[14] K. Zetter, "An unprecedented look at Stuxnet, the world's first digital weapon," Wired, Nov. 3, 2014. [Online] http://www.wired.com/2014/11/countdown-tozero-day-stuxnet/. Accessed 4/30/15.

[15] P. K. Kerr, et al., "The stuxnet computer worm: Harbinger of an emerging warfare capability," Congressional Research Services, Washington, DC,
R41524,
2010

https://www.fas.org/sgp/crs/natsec/R41524.pdf. Accessed: 5/1/15.

[16] D. Kushner, "The real story of Stuxnet: How Kapersky Lab tracked down the malware the stymied Iran's nuclear-fuel enrichment program," IEEE Spectrum, Mar. 2013, pp. 48-53.

[17] K. J. Higgins, "Stuxnet heralds new generation of targeted attacks," Information Week: Dark Reading, Sept. 23, 2010. [Online] http:// www. darkreading.com/attacks-breaches/stuxnetheralds-new-generation-of-targeted-attacks/d/did/1134420? Accessed 4/30/15

[18] "Alert (ICS-ALERT-14-281-01B): Ongoing sophisticated malware campaign compromising ICS (update B)," US Dept. of Homeland Security, Washington, DC, Dec. 10, 2014. [Online] https://ics-cert.us-cert.gov/alerts/ICS-ALERT-14281-01B. Accessed: 2/2/15.

[19] K. Zetter, "Inside the cunning, unprecedented hack of Ukraine's power grid," Wired, Mar. 3, 2016. [Online] http://www.wired.com/2016/03/insidecunning-unprecedented-hack-ukraines-power-grid/ Accessed: $3 / 7 / 16$

[20] R. M. Lee, "Thoughts on the ICS-CERT Ukraine Cyber Attack Report," in SANS Industrial Control Systems Security Blog, Atlanta, GA, USA, Feb. 25, 2016. [Online]. Available: https://ics.sans.org/blog/2016/02/25/thoughts-onthe-ics-cert-ukraine-cyber-attack-report. Accessed: $3 / 916$.

[21] M. Assante, "Confirmation of a coordinated attack on the Ukrainian power grid," in SANS Industrial Control Systems Security Blog, R. M. Lee, Ed., Atlanta, GA, USA, Jan. 9, 2016. [Online] Available: https://

ics.sans.org/blog/2016/01/09/confirmation-of-acoordinated-attack-on-the-ukrainian-power-grid. Accessed on: Jan. 15, 2016.

[22] "Alert (ICS-ALERT-H-16-056-01): Cyber-attack against Ukrainian critical infrastructure," U.S. Dept. of Homeland Security, Washington, DC, Feb. 25, 2016. [Online] https://ics-cert.uscert.gov/alerts/IR-ALERT-H-16-056-01. Accessed: $3 / 7 / 16$

[23] S. Weinberger, "Powerless in Gaza," IEEE Spectrum. vol. 46, no. 12, pp. 36-41, 2009

[24] A. B. Lovins and L. H. Lovins, Brittle Power: Energy strategy for national security. Andover, MA: Brick House Publishing Company, 1982.

[25] B. Schneier, Secrets and Lies: Digital security in a networked world. New York: Wiley Computer Publishing, 2000.

[26] S. Baker, et al. "In the dark: Crucial industries confront cyberattacks," Center for Strategic and Int. Studies, Washington, DC, 2011. [Online] 
http://www. mcafee.com/us/resources/reports/rpcritical-infrastructure-protection.pdf. Accessed: $4 / 30 / 15$

[27] P. Slovic, B. Fischhoff, and S. Lichtenstein, "Rating the risks," Environment, vol. 21, Apr. 1979 .

[28] R. Smith, "Proposal to prevent grid attack lacks power, critics say; Draft from electricity industry after assault on California substation doesn't require specific upgrades," The Wall Street Journal, Apr. 17, 2014.

[29] R. Smith, "Regulators to impose new security rules on electric utilities; FERC wants utilities to better protect substations critical to electric grid," The Wall Street Journal, Mar. 8, 2014.

[30] R. Smith, "Transformers expose limits in securing power grid," The Wall Street Journal, Mar. 3, 2014.

[31] R. Smith, "U.S. utilities tighten security after 2013 attack; PG\&E to build opaque fences in wake of sharpshooters," The Wall Street Journal, Feb. 9, 2014 .

[32] "Electric sector failure scenarios and impact analyses," Nat. Electric Sector Cybersecurity Org. Resource Workshop and Electric Power Res. Inst., Sept. 2013.2 [Online]:

https: //www. controlsystemsroadmap.net/ieRoadmap\%

20Documents/NESCOR-failure-scenarios-v2.pdf. Accessed: 5/1/15.

[33] J. Heller, "Does post-apocalyptic literature have a (non-dystopian) future? National Public Radio, May 2, 2015. [Online] http://www.npr.org/ 2015/05/02/402852849/does-post-apocalyptic-

literature-have-a-non-dystopian-future Accessed: $1 / 26 / 16$.

[34] A. Smith, "China could shut down U.S. power grid with cyber attack, says NSA chief," Newsweek, Nov. 21, 2014. [Online] http://europe.newsweek.com/ china-could-shut-down-us-power-grid-cyber-attacksays-nsa-chief-286119. Accessed: 5/1/15.

[35] "Cyber Security - Critical Cyber Asset Identification," North Amer. Electric Reliability Corporation, Atlanta, GA, CIP-002-3, Dec. 2009. [Online]

Www.nerc.com/_layouts/PrintStandard.aspx?standardnu mber $=$ CIP-002-3\&title

$=$ Cyber:20 Security $\% 20-$

\%20Critical\%20Cyber\%20Asset:20Identification\& jurisdiction=null Accessed: 5/4/15.

[36] K. J. Higgins, "Stuxnet exposes inherent problems in power grid security," Information Week: Dark Reading, Sept. 27, 2010. [Online] www. darkreading.com/attacks-breaches/stuxnetattack-exposes-inherent-problems-in-power-gridsecurity/d/d-id/1134438?. Accessed: 4/30/15.

[37] [Online] http://cybersquirrell.com/ Accessed: $1 / 25 / 16$. 